\section{DPP-4 Inhibitors: The Seinfeld of Oral Antihyperglycemics}

The popular television show Seinfeld was often described as a show about nothing. In other words, the show lacked a central theme or dogma - it simply depicted the everyday (albeit often hilarious) occurrences among 4 friends living in New York City. When reviewing the recently published cardiovascular outcome trials for the dipeptidyl peptidase-4 (DPP-4) inhibitors or "gliptins", we could not help but perceive a parallel between these medications and the popular 1990 s sitcom. Following the tradition of the fictional Seinfeld holiday Festivus, we feel compelled to "air our grievances" regarding these aggressively marketed drugs.

After the highly publicized increase in the risk of myocardial infarction (MI) observed with rosiglitazone, the US Food and Drug Administration (FDA) mandated that all new antidiabetic drugs be evaluated in phase 3 double-blind, randomized controlled trials (RCTs) adequately powered to detect differences in clinically relevant cardiovascular outcomes (cardiovascular death, nonfatal MI, nonfatal stroke), with the objective of establishing a lack of cardiovascular harm. ${ }^{1}$ Using the terms "dipeptidyl peptidase-4 inhibitor" and "cardiovascular disease", we searched PubMed from December 2008 (date of the FDA guidance document ${ }^{1}$ ) to December 2015 for RCTs published in English. The inclusion criteria were RCTs involving at least 1000 adult patients with at least 1 year of follow-up that compared a DPP-4 inhibitor with placebo and reported cardiovascular events (cardiovascular death, nonfatal MI, nonfatal stroke, or unstable angina) as the primary outcome. A total of 36 trials were initially identified; according to an independent assessment by both authors, 3 of these met the inclusion criteria. $^{2-4}$ The SAVOR-TIMI 53 trial compared saxagliptin with placebo in 16492 patients (mean age 65 years, $67 \%$ men) with type 2 diabetes mellitus and established cardiovascular disease (or at risk for cardiovascular disease). ${ }^{2}$ The EXAMINE trial compared alogliptin with placebo in 5380 patients (mean age 61 years, 68\% men) with type 2 diabetes and recent acute coronary syndrome. ${ }^{3}$ The TECOS trial randomly assigned 14671 patients (mean age 66 years, $71 \%$ men) with type 2 diabetes and established cardiovascular disease to receive sitagliptin or placebo. ${ }^{4}$ Median follow-up was $1.5-3$ years, and all 3 trials met the prespecified criteria for noninferiority for the composite cardiovascular end point as dictated by the FDA (upper bound of the $95 \%$ confidence interval $[\mathrm{CI}]<1.3)$. Thus, these glucose-lowering drugs were celebrated, both in the medical and financial sectors, for being not more harmful than nothing-hardly what most would consider to be a "feat of strength". Possibly more importantly, all 3 trials failed to show that DPP-4 inhibitors, as compared with placebo, reduced cardiovascular events.

We then performed a meta-analysis of the 3 trials $(n=36543$ patients), using a Mantel-Haenszel fixed-effect model (Review Manager, version 5.3, Cochrane Collaboration), to increase the power to detect a difference in the rate of cardiovascular events. Of note, the TECOS trial ${ }^{4}$ included admission to hospital for unstable angina, in addition to cardiovascular death, nonfatal MI, and nonfatal stroke. As with each individual trial, the results of the metaanalysis were underwhelming. There was no statistically significant difference in total cardiovascular events (risk ratio [RR] 0.99, 95\% CI 0.93-1.06) (Figure 1). Similar results were identified for all-cause mortality (RR 1.03, 95\% CI 0.95-1.11), severe hypoglycemia (RR 1.14, 95\% CI 0.95-1.38), and pancreatitis (RR 1.43,

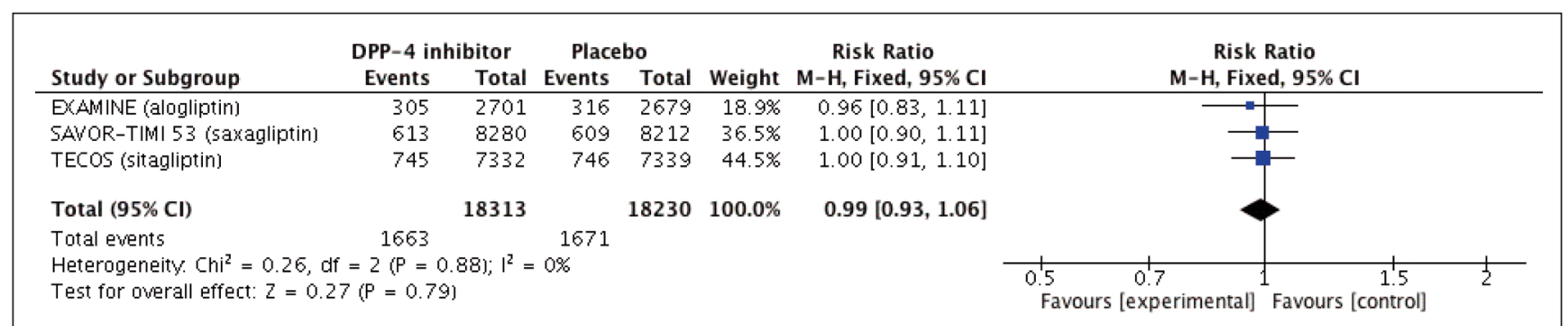

Figure 1. Forest plot for total cardiovascular events (cardiovascular death, nonfatal myocardial infarction, nonfatal stroke, or unstable angina) in patients receiving dipeptidyl peptidase-4 (DPP-4) inhibitors. EXAMINE trial for alogliptin = White and others ${ }^{3}$; SAVOR-TIMI 53 trial for saxagliptin = Scirica and others ${ }^{2}$; TECOS trial for sitagliptin $=$ Green and others ${ }^{4} \mathrm{Cl}=\mathrm{confidence} \mathrm{interval,}$ $\mathrm{M}-\mathrm{H}=$ Mantel-Haenszel. 


\begin{tabular}{|c|c|c|c|c|c|c|c|}
\hline \multirow[b]{2}{*}{ Study or Subgroup } & \multicolumn{2}{|c|}{ DPP-4 inhibitor } & \multicolumn{2}{|c|}{ Placebo } & \multirow[b]{2}{*}{ Weight } & \multirow{3}{*}{$\begin{array}{c}\text { Risk Ratio } \\
\text { M-H, Fixed, 95\% Cl } \\
1.07[0.791 .44]\end{array}$} & \multirow{2}{*}{$\begin{array}{c}\text { Risk Ratio } \\
\text { M-H, Fixed, } 95 \% \mathrm{CI} \\
\end{array}$} \\
\hline & Events & Total & Events & Total & & & \\
\hline EXAMINE (alogliptin) & 85 & 2701 & 79 & 2679 & $14.8 \%$ & & \\
\hline SAVOR-TIMI 53 (saxagliptin) & 289 & 8280 & 228 & 8212 & $42.6 \%$ & $1.26[1.06,1.49]$ & $\longrightarrow$ \\
\hline TECOS (sitagliptin) & 228 & 7332 & 229 & 7339 & $42.6 \%$ & $1.00[0.83,1.19]$ & \\
\hline Total $(95 \% \mathrm{Cl})$ & & 18313 & & 18230 & $100.0 \%$ & $1.12[1.00,1.25]$ & \\
\hline \multirow{2}{*}{\multicolumn{7}{|c|}{$\begin{array}{l}\text { Heterogeneity. } \mathrm{Chi}^{2}=3.46, \mathrm{df}=2\left(\mathrm{P}=0.18 \mathrm{j} ; \mathrm{I}^{2}=42 \%\right. \\
\text { Test for overall effect: } Z=1.91(\mathrm{P}=0.06)\end{array}$}} & \\
\hline & & & & & & & \begin{tabular}{cccc} 
& \multicolumn{1}{c}{$|c|$} & 1 \\
0.5 & 0.7 & 1 & 1.5 \\
Favours [experimental] & Favours [control]
\end{tabular} \\
\hline \multicolumn{8}{|c|}{$\begin{array}{l}\text { Figure 2. Forest plot for admission to hospital for heart failure in patients receiving dipeptidyl peptidase-4 (DPP-4) inhibitors. } \\
\text { EXAMINE trial for alogliptin }=\text { White and others }{ }^{3} \text {; SAVOR-TIMI } 53 \text { trial for saxagliptin = Scirica and others } ; \text {;ECOS trial for } \\
\text { sitagliptin }=\text { Green and others. }{ }^{4} \mathrm{CI}=\text { confidence interval, } \mathrm{M}-\mathrm{H}=\text { Mantel-Haenszel. }\end{array}$} \\
\hline
\end{tabular}

95\% CI 0.96-2.13). Repeat analyses of data for severe hypoglycemia and pancreatitis using a Peto odds ratio (for rare outcomes) produced similar results. Hospital admission for heart failure was higher with DPP-4 inhibitor therapy (RR 1.12, 95\% CI 1.00-1.25) (Figure 2); however, this result was associated with moderate heterogeneity $\left(I^{2}=42 \%\right)$ and was driven by the SAVORTIMI 53 trial. ${ }^{4}$ Therefore, this might represent either a unique property of saxagliptin or a chance finding.

None of these trials consistently reported meaningful microvascular outcomes (e.g., incident diabetic retinopathy or neuropathy, progression of chronic kidney disease), so results for these outcomes could not be combined. Previous data have shown that DPP-4 inhibitors lower glycosylated hemoglobin (A1c) by about $0.7 \%$ relative to placebo. ${ }^{5}$ As expected, A1c was lower with DPP-4 inhibitor therapy than with placebo in all 3 trials (absolute difference of about $0.3 \%$ ); however, this reduction did not translate into even a signal of benefit.

Much like an episode of Seinfeld, these drugs seem to do nothing when it comes to clinically important outcomes (benefit or harm). It may be best to ignore all the marketing hype about how these agents reduce A1c and focus on the clinically relevant evidence. In the management of type 2 diabetes, DPP- 4 inhibitors likely have a role only as add-on therapy to other agents that actually have data to support a reduction in clinically meaningful macrovascular or microvascular outcomes when insulin is not an option. We recommend either using an antidiabetic agent with better data or doing nothing — not that there's anything wrong with that.

\section{References}

1. Guidance for industry: diabetes mellitus — evaluating cardiovascular risk in new antidiabetic therapies to treat type 2 diabetes. Silver Spring (MD): US Department of Health and Human Services, Food and Drug Administration, Center for Drug Evaluation and Research; 2008 Dec [cited 2015 Oct 14]. Available from: www.fda.gov/downloads/drugs/guidancecomplianceregulatoryinformation/ guidances/ucm071627.pdf

2. Scirica BM, Bhatt DL, Braunwald E, Steg PG, Davidson J, Hirschberg B, et al.; SAVOR-TIMI 53 Steering Committee and Investigators. Saxagliptin and cardiovascular outcomes in patients with type 2 diabetes mellitus. N EnglJ Med. 2013;369(14):1317-26.

3. White WB, Cannon CP, Heller SR, Nissen SE, Bergenstal RM, Bakris GL, et al.; EXAMINE Investigators. Alogliptin after acute coronary syndrome in patients with type 2 diabetes. N Engl J Med. 2013;369(14):1327-35.

4. Green JB, Bethel MA, Armstrong PW, Buse JB, Engel SS, Garg J, et al.; TECOS Study Group. Effect of sitagliptin on cardiovascular outcomes in type 2 diabetes. NEngl J Med. 2015;373(3):232-42.

5. Park H, Park C, Kim Y, Rascati KL. Efficacy and safety of dipeptidyl peptidase-4 inhibitors in type 2 diabetes: meta-analysis. Ann Pharmacother. 2012;46(11): 1453-69.

Arden R Barry, BSc, BSc(Pharm), PharmD, ACPR

Chilliwack General Hospital

Lower Mainland Pharmacy Services

Chilliwack, British Columbia

Faculty of Pharmaceutical Sciences

University of British Columbia

Vancouver, British Columbia

Ricky D Turgeon, BSc(Pharm), PharmD, ACPR

Vancouver General Hospital

Lower Mainland Pharmacy Services

Vancouver, British Columbia

Competing interests: None declared. 